\title{
Knowledge Regarding Management of Selected Medical Emergencies among Registered Nurses: A Cross-Sectional Survey
}

\author{
Sreelakshmy .U .R ${ }^{1}$, Haseena T. A. ${ }^{2}$ \\ ${ }^{1}$ Assistant Professor, Sree Gokulam Nursing College, Trivandrum, India \\ ${ }^{2}$ Head of the Dept., Medical surgical nursing, Sree Gokulam Nursing College, Trivandrum, India
}

\begin{abstract}
Emergency is a situation in which patients require immediate care . Recognition of life threatening illness or injury is one of the important aspects of emergency care. Before a diagnosis can be made, recognition of dangerous clinical signs and symptoms with initiation of interventions to reverse or prevent a crisis is essential. Prompt identification of patients requiring immediate treatment is an essential nurse competency in an emergency department. This study was intended to assess the knowledge regarding management of selected medical emergencies among registered nurses. The objectives of the study were to assess the knowledge of registered nurses regarding management of selected medical emergencies and to determine the association of knowledge score and selected demographic variables like age, gender, professional qualification, clinical experience and area of experience. Methodology: The research approach adopted was quantitative research approach. The study was conducted among 90 registered nurses working in Sree Gokulam Medical College and Research Foundation, Venjaramoodu. After obtaining consent from registered nurses, structured knowledge questionnaire was given to the samples. The data thus collected were analysed using descriptive and inferential statistics. Results: Analysis revealed that $56.7 \%$ registered nurses had average knowledge,26.6\% has good knowledge and only $16.7 \%$ has poor knowledgeregarding management of selected medical emergencies. There was significant association between knowledge score and selected demographic variable such as area of clinical experience of registered nurses.
\end{abstract}

Keywords: Knowledge; Registered nurses; Medical emergencies

\section{Introduction}

Emergency is a situation in which patients require immediate care. Emergency situations can occur at any time. Nurses play a crucial role in providing care in emergency conditions.

Emergency nursing care is a specially designed and equipped facility, staffed by skilled personnel to provide effective and safe care for dependent patients with life threateningor partially life threatening problems. The nurses should have additional education in health assessment, diagnosis, management of illness and injuries including ordering and integrating the results of the test and prescribing medication. Their practices emphasize health promotion and illness prevention. The concept of Emergency Nursing Care took its root from Florence Nightingale who is the founder of Modern Nursing. She placed seriously ill patients near the nurses ${ }^{\text {ee }}$ station for closer and better observation and care.

During the past ten years the demands on emergency nursing have been increasing because of the changing health care needs of the society. Because of the current health care crisis one of every three persons are seeking care in the emergency department.

It is also reported that persons seeking emergency care at hospital over a 24 hour period have the problems as chest pain, diarrhea, dyspnoea, accidental injury, epilepsy,head injury, hemorrhage, dizziness, abdominal pain, behavioral problems as well as toxological emergencies, i.e. poisons, sting and snake bites.

\section{Background and need of the study}

Emergency department is the heart of the hospital. Emergency nursing is exciting and unique specialty area and nurses in emergency department are vital members of health care delivery system. It is necessary for nurses to possess a high degree of knowledge, skill and clinical expertisewith a strong emphasis on communication skills, patient assessment and setting priorities.

Data on the global burden of disease have shown that cardiovascular diseases will soon become the leading cause of death worldwide, killing close to 15 million people in the world each year. Projections of mortality, taking into account the expected increases in population and increased life expectancy, suggest that cardiovascular diseases will be the leading cause of mortality, measured as "lost years of life," and the leading cause of "years lived with disability" in all parts of the world by the year 2020 .

A study conducted in queen Elizabeth hospital, London, highlights the need to identify and fast-track patients with an acute coronary syndrome so that thrombolysis or appropriate interventional care can take place as soon as possible, to optimize myocardial salvage and reduce door-to-needle time It is therefore extremely important that nurses in acute clinical areas are able to record and interpret 12-lead electrocardiograms so that the treatment modality can be initiated as soon as possible, leading to better upgrade their knowledge. ${ }^{2}$

Poisoning is a common mis happening occurring in houses particularly amongst the children and women. Maryland 


\section{International Journal of Science and Research (IJSR) \\ ISSN (Online): 2319-7064 \\ Index Copernicus Value (2013): 6.14 | Impact Factor (2015): 6.391}

Institute of Emergency Medical Services describes the time immediately after an emergency as the „Golden hour "e when the life hangs in a balance which can be saved by administration of right medications and emergency care.In Asia, the case fatality with pesticide poisoning is $10-20 \%$. Pesticides are commonly used for intentional self poisoning due to its easy availability.

A survey conducted on Intensive care management of organophosphate insecticide poisoning at Turkey revealed that 32 (68\%) patients were suicidal attempts and 15 (32\%) were accidental exposure. Forty four (93.6\%) of the patients were poisoned through gastro intestinal route, 1 (2.1\%) through inhalation and 2 (4.2\%) through intravenous route. The estimated average time for admission to emergency department after the exposure was 9to 4 hours The researcher found that mortality rate for patients who required mechanical ventilation was $50 \%$ and $21.6 \%$ do not require ventilator support. The duration of intensive care stay was 35 days. Thus the researcher felt that organophophorus insecticide poisoning is a serious condition which needs rapid diagnosis and treatment and careful monitoring, appropriate management and early recognition may decrease the mortality rate among these patients. ${ }^{3}$

India is home to large numbers of individuals with epilepsy. Epidemiological studies in India have shown epilepsy to rank first or second amongst the neurological diseases seen in India. The annual incidence of epilepsy in India is approximately $40-50$ per 100,000 per year. While this is lower than some other developing nations, the actual numbers of individuals suffering from epilepsy in India are very high and hence epilepsy assumes public health importance $^{4}$

A study was conducted at three University hospitals in Tanta, Menoufiya and Zagazig to assess the nurses' knowledge and attitudes towards epilepsy. Sample consisting of 273 nurses working in different hospital departments, The results revealed a deficiency in the nurses' knowledge about epilepsy. However, they had a moderately positive attitude towards epilepsy. It is recommended that all in-service training programs for nurses should emphasize epilepsy management, rehabilitation of epileptics, and how to change public attitudes towards epilepsy ${ }^{5}$

\section{Review of Literature}

An experimental study was conducted to assess the knowledge of nursing personnele ${ }^{\text {ee }}$ on first 24 hours care of the patients with Myocardial Infarction in Osmania General Hospital, Hyderabad. 50 nursing personnel's were randomly selected and structured questionnaire was used for data collection. The results of the study showed that 26 per cent of nursing personnel ${ }^{\text {ee }} \mathrm{s}$ had below average knowledge, 44 per cent had average level of knowledge, and 30 per cent had above average knowledge. The study concluded by saying that the nurses need to be given special training in cardiac patients in ordered to improve their knowledge. ${ }^{6}$

A study was conducted to assess the knowledge of staff nurses related to management of poisoning in an emergency department at V. M Hospital, Tamilnadu. Ninety two staff nurses were selected. Data were collected by using closed ended questionnaire, which consisted of 24 items pertaining to knowledge of staff nurses regarding management of poisoning in emergency department.. The findings on knowledge of management of poisoning revealed that most (34.78\%) of staff nurses had average knowledge. No association ( $\mathrm{p}<0.05)$ was found between knowledge scores and demorgraphic variables. The study concluded that level of knowledge of staff nurses regarding management of poisoning in ED was inadequate. ${ }^{7}$

A quantitative assessment of the impact of an epilepsyfocused training program on school nurses was conducted. The Epilepsy Foundation and the National Association of School Nurses (NASN) created a training program titled "Managing Students with Seizures" to educate school nurses on strategies and resources that they can use to handle emergency situations effectively and to create a safe and supportive school environment for children with epilepsy and seizures. Before and after the training sessions, nurses answered questionnaires that measured their confidence levels in providing care for students with epilepsy and seizures; these questionnaires showed an improvement in nurses' confidence levels across all measures. Analysis was also carried out to identify program components and nurse subgroups associated with statistically significant improvements. An evaluation of satisfaction indicated overall satisfaction with the program ${ }^{8}$

A survey was conducted among nursing staff from a Pediatric Epilepsy Monitoring Unit regarding the assessment and nursing care of various types of seizures potentially seen in a pediatric epilepsy monitoring unit. Staff nurses in a Pediatric Epilepsy Monitoring Unit (EMU) have expressed a knowledge deficit in differentiating among types of seizures as well as a deficit in self-efficacy (confidence) in seizure management. It is especially important for the staff nurse to understand the various types of seizures as well as the appropriate interventions to safely direct the nursing plan of care. This unit based nursing led research study was intended to ascertain whether an education intervention with nursing staff regarding the assessment and care of the pediatric epilepsy patient will increase staff nurse knowledge and self-efficacy to ultimately improve the safety and quality of care of this vulnerable population. ${ }^{9}$

\section{Objectives}

- To assess the knowledge of registered nurses regarding management of selected medical emergencies.

- To determine the association between knowledge and selected socio demographic variables

\section{Assumption}

Registered nurse will have some knowledge regarding management of cardiac emergencies, epilepsy and poisoning. 


\section{International Journal of Science and Research (IJSR)}

ISSN (Online): 2319-7064

Index Copernicus Value (2013): 6.14 | Impact Factor (2015): 6.391

\section{Validity and Reliability}

Content validity was done by 5 experts from the field of nursing. There was $100 \%$ agreements among the experts regarding the item coverage. Internal consistency was calculated using split half method and was found to be 0.88 . Stability of the tools was established using test- retest method and was found to be 0.8

\section{Research design and approach}

- Approach : Quantitative

- Design : Descriptive design

\section{Sampling Technique}

- Setting : Sree Gokulam Medical College

- Population :Registered nurses

- Sample :Registered nurses working in Casualty, Medical ICU, Coronary Care Unit and Neuro ICU and Post basic and MSc nursing students

- Sample Size : 90

- Sampling Technique : convenient sampling

\section{Tools and Techniques}

In this study tool consists of demographic data of registered nurses and structured knowledge questionnaire to assess the level of knowledge regarding management of selected medical emergencies. Technique used was Self- reporting.

\section{Analysis and Interpretation}

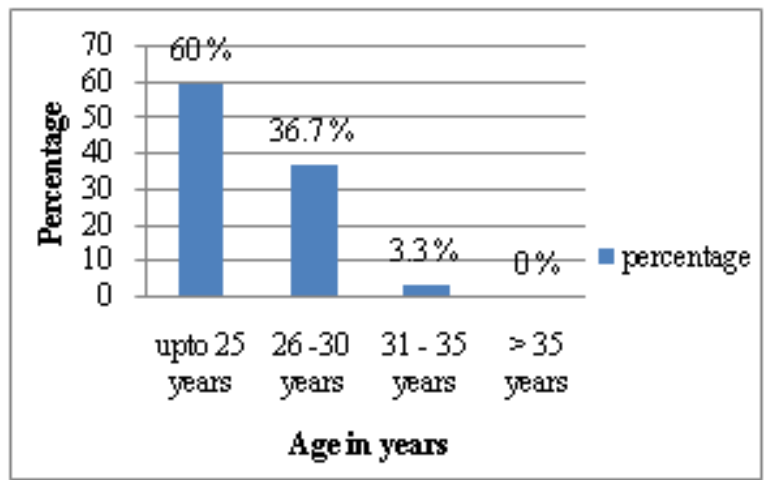

Figure 1: Distribution of samples according to age

Figure 1 shows that $60 \%$ were in the age group of up to25yrs and $36.7 \%$ belongs to $26-30 y$ rs of age. Only $3.3 \%$ were in the age group of 31-35 yrs and none of them belongs to age group greater than 35yrs.

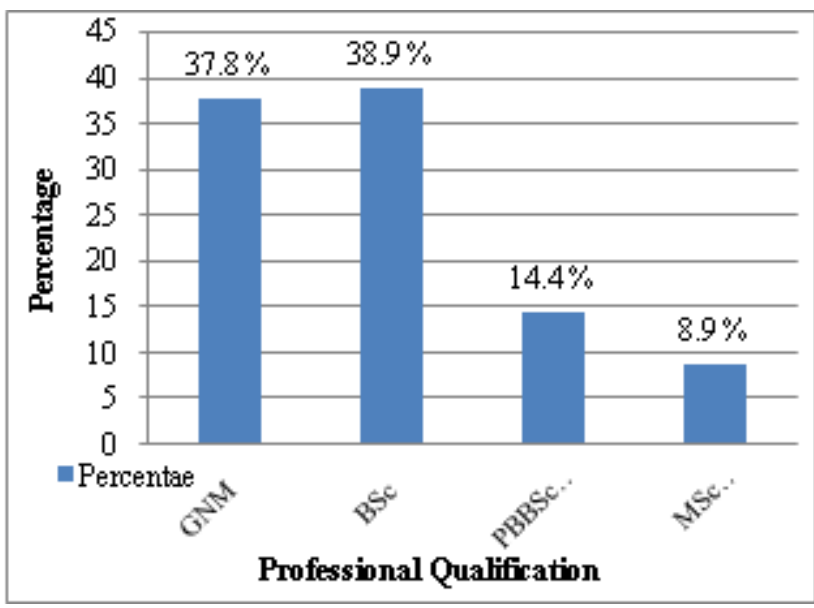

Figure 2: Distribution of sample according to professional qualification

Figure 2 shows that $38.9 \%$ have BSc degree and $37.8 \%$ have GNM as their professional qualification.14.4\% were doing PBBSc nursing and only $8.9 \%$ were doing MSc nursing .

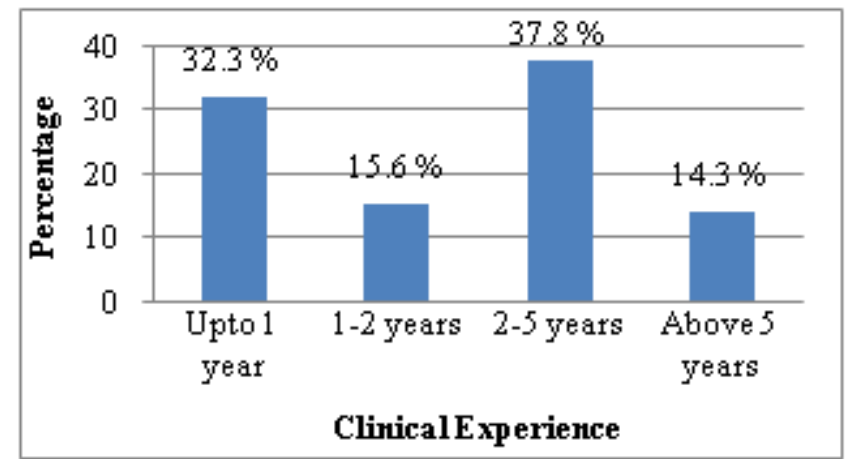

Figure 3: Distribution of sample according to clinical experience

Figure 3 shows that $37.8 \%$ of registered nurses has $2-5 y r s$ of experience, $32.3 \%$ has up to $1 \mathrm{yr}, 15.6 \%$ has 1 -2years and only $14.4 \%$ has greater than $5 y r s$ of experience.

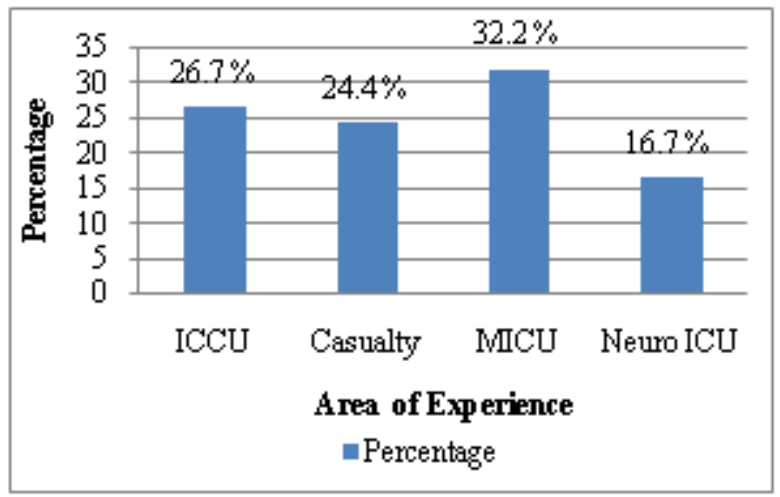

Figure 4: Distribution of sample according to area of experience

Figure 4 shows that majority of samples $32.2 \%$ belongs to MICU, 26.7 \%from ICCU, 24.4\% havecasuality experience and $16.7 \%$ belongs to NICU 


\section{International Journal of Science and Research (IJSR) \\ ISSN (Online): 2319-7064}

Index Copernicus Value (2013): 6.14 | Impact Factor (2015): 6.391

Table 1: Distribution of knowledge score of registered nurses regarding management of selected medical emergencies, $n=90$

\begin{tabular}{|c|c|c|}
\hline Grading & Frequency & Percentage (\%) \\
\hline Poor & 15 & 16.7 \\
\hline Average & 51 & 56.7 \\
\hline Good & 24 & 26.6 \\
\hline Total & 90 & 100 \\
\hline
\end{tabular}

The data presented in table 1 shows that majority 51 (56.7\%) had above average knowledge, whereas 24 (26.6\%) has good knowledge and only 15(16.7\%) has poor knowledge regarding management of selected medical emergencies

Table 2: Association between knowledge score and selected demographic variables

\begin{tabular}{|lcccccc|}
\hline $\begin{array}{l}\text { Demographic } \\
\text { Variable }\end{array}$ & Poor Average Good & $\gamma^{2}$ & $\begin{array}{c}\text { df } \\
\text { Level of } \\
\text { significance }\end{array}$ \\
\hline $\begin{array}{l}\text { Area of experience } \\
\text { ICCU }\end{array}$ & 1 & 15 & 8 & 27.4 & 6 & $\mathrm{P}<0.05$ \\
Casualty & 10 & 9 & 3 & & & \\
MICU & 1 & 24 & 4 & & & \\
Neuro ICU & 3 & 3 & 9 & & & \\
\hline
\end{tabular}

The data presented in table 2 shows that there was significant association between knowledge score and area of experience of registered nurses $(\mathrm{P}<0.05)$.

\section{Discussion}

In the present study majority $56.7 \%$ of registered nurses had average knowledge, 26.7\% had good knowledge and16.7 \%)had poor knowledge regarding management of selected medical emergencies.

This was supported by a study conducted in NTR University of health sciences, Vijay Wada which showed that 26 per cent of nursing personnele ${ }^{\text {ee }}$ s had below average knowledge, 44 per cent had average level of knowledge, and 30 per cent had above average knowledge regarding the first 24 hours care of patients with Myocardial infarction ${ }^{19}$

Computed Chi-square $\left(\chi^{2}\right)$ test proved that there is significant association between knowledge score of registered nurses with the area of experience and there is no significant association between knowledge score and socio demographic variables such as age, gender, professional qualification and clinical experience.

This was supported by a study conducted in NTR University of health sciences, Vijay Wada which showed that there was significant association between nurses knowledge and area of experience and educational qualification ${ }^{19}$

\section{Nursing Implications}

The findings of this study have implications on nursing practice, nursing education, nursing administration and nursing research.

\section{Nursing Practice}

1)Implement emergency management measures of selected medical emergencies in nursing practice to improve the quality of care delivered.

2)Arrange in service education programme regarding emergency management techniques

\section{Nursing education}

1)Emergency management measures of selected medical emergencies can be included in clinical teaching strategies.

2)Arrange hands own training to nursing students regarding management of medical emergencies

\section{Nursing Administration}

1)The nurse administrators can take initiative in promoting educational sessions to registered nurses

2)Nurse administrators can see that all staffs in the ICUs and ward are trained about emergency management techniques

3)Nurse administrators should arrange in- service education programme regarding emergency management techniques

4)Administrators can formulate policies regarding management of medical emergencies

\section{Nursing research}

1) Research can be done to identify the effectiveness of structured teaching programme on knowledge and practice regarding management of selected medical emergencies

2) Research can be done to assess the effect of hands on skill training programme in managing patients with emergencies

3) Research can be done to assess the knowledge regarding management of other medical emergencies

\section{Limitations of Study}

The study was limited to Sree Gokulam Medical College and Research Foundation which imposes limits on generalization

\section{Recommendations}

In the light of the findings of this study and from personal experience of the investigators, the following recommendations are put forth:

- A similar study can also be replicated on large sample.

- Educational sessions regarding emergency management of selected medical emergencies should be drawn up and implemented in different settings

- Effective utilization of mass media should be done for propagating information about emergency management of selected medical emergencies

- In service education should be provided to staff nurses to update their knowledge regarding emergency management of selected medical emergencies.

\section{Conclusion}

The study was able to show that registered nurses had average knowledge regarding management of selected medical emergencies. It was also concluded that there was 


\section{International Journal of Science and Research (IJSR) \\ ISSN (Online): 2319-7064}

Index Copernicus Value (2013): 6.14 | Impact Factor (2015): 6.391

significant association between knowledge score and the selected demographic variable such as area of clinical experience of registered nurses

\section{Acknowledgement}

The author express her sincere thanks to respected Principal Lt.Col.Meera K Pillai, Mrs.Haseena, HOD, Dpt of .Medical-Surgical Nursing, SreeGokulam Nursing College, SreeGokulam Medical College and Research Foundation, Trivandrum for their kind support and guidance throughout the study.

\section{References}

[1] BriethardtGunther,EckardtLars. The global burden of cardiovascular diseases. Available from :http//onlinelibrary.willey.com.

[2] Docherty B. Lead and ECG interpretation and chest pain management.Br J Nurs. [Serial online] 2010 Nov 27- Dec 10 [cited 2008 Aug 12]; 12(21):[P.1248-55]. Available from URL: http://:www.ncbi.nlm.nih.gov/sites/entrez.

[3] Murat Singur, MuhammedGuven. Intensive Care Management of Organophosphate insecticide poisoning. Critical care. 2009; 5 (4): 93-98

[4] Gouri-devi M, gururaj g, Satishchandra $P$ et al Prevalence of neurological disorders in Bangalore, India: a community based study with a comparison between urban and rural areas. Neuroepidemiology2010 ;23:261-268.

[5] Ahmed NI, Aly SA, Shaaban EMThe nurses' knowledge and attitudes about epilepsy.Br J Nurs. [Serial online] 2008 Nov 27- Dec 10 [cited 2008 Aug 12]; 12(21)[P.1248-55].Availablefrom

URLhttp://:www.ncbi.nlm.nih.gov/sites/entrez

[6] KonkiJhanslilaxmibai. "Knowledge of nursing personnel on first 24 hours care of patients with Myocardial infarction in Hyderabad". Unpublished thesis NTR University of health sciences Vijay Wada. September 2011.

[7] Krishan R.N., Darshan K. Annual national conference of the society for emergency medicine. Nov2008;www.pubmed.gov.

[8] Austin JK, Kakacek JR, Carr D. Impact of training program on school nurses' confidence levels in managing and supporting students with epilepsy and seizures.JSchNurs.[cited2010Aug12];AvailablefromUR L:http://:www.ncbi.ncm.nih.gov/sites/entrez.

[9] Gina Bufe, Karen Eck,Susan Jacob, Josephine Marcantonio. Utilizing an Education Intervention to Improve the Quality of Nursing Care for Pediatric EpilepsyMonitoringUnitPatients.JSchNurs.[cited2010A ug12];AvailablefromURL:http://:www.ncbi.ncm.nih.go v/sites/entrez

\section{Author Profile}

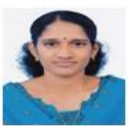

Mrs. Sreelakshmy.U. R, MSc (N) completed her Masters in Nursing in Medical-Surgical Nursing Specialty (Neuro Science Nursing) from Upasana College of Nursing, Kollam and was graduated from Lisie College of Nursing, Ernakulam. She is currently working as
Lecturer in Department of Medical-Surgical Nursing, SreeGokulam Nursing College, Sree Gokulam Medical College and Research Foundation, Venjaramoodu, Trivandrum, Kerala.

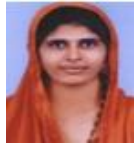

Mrs. Mrs. Haseena T A, MSc (N) is currently working as Associate Professor and Head of the Department, Medical Surgical Nursing, Sree Gokulam Nursing College, Trivandrum. She completed her Bachelors in Nursing from Sree Balaji College of Nursing and received her Master"s in Nursing with first rank from Meenakshi College of Nursing, Chennai. Currently, she is doing PhD under INC, National Consortium. She has been a resource person for various national conferences and also has published research papers in national and international journals. 